\title{
The Effect of Team Choice in Ingress and Pokémon GO for Players' Social Circles and Attitudes Towards Game Slang
}

\author{
Samuli Laato \\ University of Turku \\ sadala@utu.fi
}

\author{
Nobufumi Inaba \\ University of Turku \\ nobufumi.inaba@utu.fi
}

\author{
Mauri Paloheimo \\ University of Turku \\ mauri.paloheimo@utu.fi
}

\begin{abstract}
Player communities in the location-based games Pokémon GO and Ingress differ from most online multiplayer game communities in two major ways: (1) Interaction between players occurs mostly face-to-face and (2) teams are static, for example, currently in Pokémon GO, changing teams is possible only once a year. In addition, much of the interaction between teams is non-verbal and occurs in the game world. The current study investigates how these characteristics affect the forming of player communities and friendships, and how the team of Pokémon Go and Ingress players can be used to predict the usage and attitudes towards a slang-word "jym" i.e. gym. Five Pokémon GO chats (242852 messages) from South-Western Finland were analyzed. In addition, a questionnaire $(N=178)$ was sent to players in the case community, asking about their opinions and attitudes towards the word "jym". The results highlight the importance of the team in location-based games for the forming of friendships and raise an issue that the lack of verbal communication and cooperative opportunities can lead to negative attitudes and prejudice towards players on the opposing team. The study shows the influence of exclusive team chats on players' attitudes and draws parallels to the polarization of opinions due to personalized search results and social media. Game mechanics which encourage players from different teams to cooperate with one another are proposed as a solution for the polarization.
\end{abstract}

\section{Introduction and Background}

Ingress and Pokémon GO are location-based pervasive games, created by Niantic. Both games are published for Android and iOS platforms, and their main gameplay is based on the players avatar location corresponding to the players location in the real world. Players see a map of their surroundings on the main user interface, and are prompted to navigate to points of interest (PoIs) visible on their screen. Unlike the majority of multiplayer online games, location-based games (LBGs) such as Ingress and Pokémon GO, make players meet each other in the real world, and interaction while playing happens mostly face-to-face instead of online [1, 2, 3, 4]. Social interaction is boosted by several design decisions which reward players from interacting with one another [5]. This can lead to an increase in players' cooperative behavior [6].

Social communities revolving around a common hobby are of course nothing new. Sports and other hobbies have united people long before the age of the internet [7], and even after multiplayer computer games started to rise in popularity, players have arranged LAN -parties, gaming events and other activities where they physically meet each other [8]. LAN parties and traditional sports such as football games and basketball games require attendance in a fixed location at a fixed time. By contrast, even though LBGs can have synchronous cooperative events such as raids in Pokémon GO [9] or item farms in Ingress, the main game can be played alone. When playing LBGs, real life interactions can occur randomly with whomever else might be playing at the same time, or even with people unrelated to the game[10]. These types of spontaneous interactions with strangers are less likely to happen, for example, in a LAN party.

Even outside playing the game, LBG players are united by a common passion for the game [11]. As interaction takes place in the real world, LBGs are less likely to suffer from cyberbullying and toxicity, which are an issue in several popular online multiplayer games [12, 13, 14]. LBGs such as Pokémon GO also have diverse playerbases, with basically all genders and age groups being represented [15]. Contrary to some prior studies on communities surrounding gaming [16], gender does not correlate with the probability of a person playing Pokemon GO [11]. Having the opportunity to interact with fellow players, who are in a completely different situation in life, can be seen as an enriching and eye-opening experience. This can 
also have a positive effect on players' attitudes and understanding towards multiculturalism [17].

Despite the many positive effects LBGs are likely to have on their players social life and activity, there are some negative behavioral consequences which might arise from playing these games, including risen tendency to trespass on private property, cross streets on red lights and park cars in illegal spots [18]. These tendencies might further impact players social relationships, perhaps not with other players, but with people who are not familiar with LBGs. In addition, as in Ingress and Pokémon Go players are split into static teams, ingroup-outgroup type of behavior can emerge [19]. While an ingroup vs outgroup setup serves to increase cooperation between players in the same team, it may alienate players' in the opposing team [20]. This can have consequences on players attitudes on the members of the opposing teams $[19,21,22,23,20]$. However, as LBGs differ in design [24], a more detailed observation of the gameplay and communities of LBGs is required before conclusions can be drawn.

\subsection{Ingress players communities}

Ingress was released in late 2012, and is sometimes referred to as the predecessor of Pokémon GO [25]. It is also referred to as a pervasive game or a mixed reality game, highlighting the blur between playing and real world [26]. As of 2019, Ingress is still over 10 times less popular than Pokémon Go, while still being the second most popular LBG in the world [24]. Currently, there are two teams in the game, referred to as factions: Enlightened and Resistance. Players choose a faction in the very beginning before they can start playing, and faction change is only possible after reaching level 16 (which takes a long time) and then "recursing" to start all over from level one. Team change can in theory also be done by personally appealing to Niantic, however, if the team is changed manually by Niantic, the player loses all accumulated progress and items, only keeping their medals.

The goal of Ingress is to travel to PoIs called portals, capture them and link them together to create triangles [27]. Once a triangle is made, the area inside switches color to match the players team. Ingress-players can also focus on the game without actively playing it, by, for example, following the actions of certain key players in the opposing team. This kind of meta-playing and speculation concerning, for example, possible big field operations of the enemy team requires effective communication among members of the same faction. Even though the game contains various sorts of activities for members of the same faction, there are no in-game activities which require cooperation between factions, unless rare special events such as field art is taken into account. Instead, the factions are opposed to each other in every turn and most in-game activities which benefit one faction harm the other, giving birth to an ingroup-outgroup setting [19]. The design of Ingress not only splits players into two teams [27], but also influences the social relationships so that members of the same team are likelier to become friends than two players from opposing teams [16, 5, 28].

The problem of social polarization due to the two Ingress factions has been loosely addressed by in-game social events like FirstSaturday, XM Anomaly and Mission Day [29]. In addition, independent organizers have constructed, for example, field museums using the game Ingress, which are aimed at players of both factions [30]. Nonetheless, Ingress players remain enthusiastic about the social dimension of the game [25], meaning that perhaps it is not a problem that roughly half the people playing are always considered opponents in-game. In fact, previous studies highlight the positive effects Ingress has on team spirit, joint commitment, social identity and attitudes towards cooperation [5]. Also as Ingress players cannot destroy portals of members from their own faction, the opponents are "needed" to clear the playing field every once in a while [27].

\subsection{Pokémon GO player communities}

When Pokémon GO was released in summer 2016, it immediately exploded in popularity with hundreds of millions of downloads within the span of a few months. Pokémon GO has been found to increase physical activity, at least in the short term [31], and also to have the potential to activate socially withdrawn people [32] and reduce sedentary behavior [33]. The game can increase geographical knowledge, navigational skills and knowledge of local surroundings [34]. In addition, social communities, which serve to activate people, have formed around the game [35]. However, there are also drawbacks to the game, for example, privacy, security and safety issues [36].

Social interaction is currently promoted by Pokémon GO gameplay decisions in several ways. There are raid bosses in the game, which are essentially strong enemies that requires the help of other players to beat [9, 37]. Raids appear (pseudo)randomly on gyms, which are located on specific predetermined locations. Coordinating raids and sharing information about their locations is common practice in several Pokémon GO communities [9]. In addition to raids, Pokémon GO features two gameplay elements which, to work, 
requires to be in the proximity of other players: trading and PvP battling [38]. Players receive rewards from both activities: trading enables people to share Pokémon with each other and PvP battling yields some small item rewards up to three times a day. In addition, Pokémon GO players get together to play the game just for fun, as there are no negative repercussions from playing with friends, except possibly some conflict related to gyms [39].

Similarly to Ingress [5], Pokémon GO players share exclusive communities reserved only for the members of the same team [4], fostering ingroup-outgroup behavior [19, 21, 40, 22]. Currently, there are three teams: Valor, Instinct and Mystic. These teams play a role in gym battles and gym control, as well as a small role in raids, where the team that makes the most damage and the team that controls the gym receive minor extra rewards. Arguably teams in Pokémon GO play a lesser role than in Ingress, as the main game mechanics of capturing Pokémon, trading, hatching eggs and raiding can all still be done together with players from other teams without a penalty [39].

\subsection{Language acquisition in gaming communities}

LBGs such as Pokémon GO prompt players to spontaneously acquire information from their surroundings while playing, making the game ideal for learning language [41]. Especially young children have been shown to acquire and adopt language and words when playing games [42]. Language develops naturally when people balance the cost and effectiveness of their word choices [43]. For example, in case a word is extremely long and troublesome to say, humans are prone to attempt to find replacements for it. Games such as Pokémon GO and Ingress set a unique challenge to communities of non-English speakers when a translation of the game is not available. For example, in Finland, local Ingress and Pokémon GO communities use predominantly Finnish when discussing game-related phenomenon, and as there are no Finnish translations of the games, players casually mix English words into their sentences which otherwise follow Finnish grammar. As foreign words might be difficult to pronounce, players are coming up with their own slang [44]. Due to the high level of required cooperation in Ingress and Pokémon GO [5] and the divisive nature of teams, these slang terms can emerge in a single team, but never reach popular acceptance [44].

Several new words and slang phrases have been invented in other online multiplayer game communities besides Pokémon GO and Ingress. Examples of words and phrases which have reached global success include "get rekt", "N00b" [12] and "1337" or "133t" [45]. The mechanisms how the words travel have a lot to do with the player communities, and the spreading is accelerated whenever popular gaming figures adopt the words. These kinds of phrases have reportedly been spread, for example, via the chat on the popular game streaming platform twitch.tv [46]. In addition, slang-terms used by players of the opposing team can receive negative associations, thus, giving birth to negative attitudes towards the words [43]. This effect is predicted to be stronger with the game Ingress, which has less cooperation possibilities between teams than Pokémon GO.

\subsection{Objectives and Research Questions}

The purpose of the current study was to investigate the social communities that have formed around LBGs Pokémon GO and Ingress. With a unique research setup where players between teams had minimal verbal interaction with one another, but a lot of conflict interaction through the game world, the birth of team cultures and polarized opinions were expected to emerge $[19,47]$. These opinions were expected to be linked to the general opinion of the players' team, as social influence has been found to affect player behaviour in online games [48]. An initial observation of Pokémon GO and Ingress player communities in South-Western Finland revealed players to have polarized opinions towards a slang-term "jym", where some factions seemed to use the term freely while others had negative attitudes towards it. Therefore, attitudes and usage of the word "jym" were studied. The research questions concerning the word "jym" where formulated as follows: RQ1: "Are there differences in the adoption, attitudes and usage of the word "jym" between Pokémon GO and Ingress teams?" RQ2: "Do players attitudes towards the word "jym" correlate with how often and in what manner the term is used in local exclusive team chats?" Based on theories of group polarization [48], ingroup-outgroup thinking [19], examples from social media $[49,50]$ and prior knowledge of the case community, differences and polarization in peoples' opinions were expected to emerge and these were expected to correlate with the players' team.

\section{Methods}

\subsection{Choosing the word(s) for analysis}

In an initial analysis of language usage in Ingress and Pokémon GO communities in Finland, slang terms for many items and events in both games were 
discovered. These included words based on the names previous names of Ingress items, for example, calling the Aegis shield "axa" (based on an old sponsorship deal) or calling the Circle-K and Lawson power cubes "sponssicube", based on the fact that they are named based on a sponsorship deal. The issue with these words in relation to the research question, is that they were game-specific and did not cross the border of the two Niantic games. Also the words seemed to be already widely accepted in the local communities by members of all teams.

A controversial opinion-dividing term "jym" was discovered among Pokémon GO players. The word was also well known among Ingress players, firstly because many of them also played Pokémon GO, and secondly because some players had submitted new portal candidates to the Niantic PoI database [51, 52], which contained the slang-word "jym". "Jym" was perceived by players to mean outdoor gyms. Based on initial review of chat logs, players attitudes towards the word seemed not only polarized, but also surprisingly strong. Therefore the current study chose to follow the usage, adoption and attitudes towards the word "jym".

\subsection{Data collection}

Players' reactions to the use of "jym" were followed in local chat groups. All in all, five different chat groups were analyzed from Pokémon GO. The Pokémon GO chats were two for team Mystic, one team Valor and one for team Instinct and one where members from all three teams were present. The first three chat groups were open to all members of the specific team and were considered the primary chats in the community. The last two chats were smaller exclusive chats. The data from the chat groups was collected during the following periods: Case 1 Mystic (August 2017-March 2019), case 2 Valor (July 2018- July 2019), case 3 Instinct (September 2016-April 2019), case 4 common chat (October 2017-January 2019), case 5 Mystic chat 2 (May 2018-March 2019). Almost all data in the chats was in Finnish, with minor exceptions of conversation in English. Chat participants' identity was protected via anonymization and careful handling of the data.

In addition, an online questionnaire was sent to Pokémon GO and Ingress players in South-Western Finland on July 10th 2019 where permission to participate in the study was also asked. Participants who did not give permission to use their answers in research were excluded. Also participants who replied to the questionnaire, but who failed to provide a valid player name, were excluded. The questionnaire was open for one day and distributed directly to the very chats analyzed in the current study, and contained the following questions:

1. Are you familiar with the term "jym"? (yes, no)

2. Are you actively using the term "jym" yourself? (yes, no, sometimes)

3. In case you do not say "jym", what do you say instead? (open question)

4. What sort of feelings does the term "jym" arise in you? (positive, neutral, negative)

5. State your team in Pokémon GO (Valor, Instinct, Mystic, I do not play Pokémon GO)

6. State your team in Ingress (Resistance, Enlightened, I do not play Ingress)

7. How old are you? (Below 18, 18-25, 26-40, 41-60, over 60)

8. State your username in Ingress and Pokémon GO. (open text field)

The questionnaire data was paired to the data obtained from chats by using the player name as an identifier. In addition to chat data and the questionnaire, game data of portals which had "jym" in their name were tracked for the purpose of establishing the penetration of the slang word into the game world itself via accepted portal candidates containing the word "jym". Finally, participants who replied differently to the questionnaire than what results from the qualitative analysis of the chat logs suggested, were interviewed face-to-face in order to gain insight on why this was the case.

\subsection{Measuring attitudes towards the word}

A qualitative analysis was conducted on the group chats. In Telegram and WhatsApp chats, "jym" term was searched, and surrounding discussion was read in order to find out players perceptions and attitudes towards the word. Players were reported to either have a positive, negative or neutral attitude towards the word. The times the word appeared naturally and the times the word was discussed specifically were recorded. In unclear cases, for example, where a different attitude was recorded in various instances, the most recent recordings were held in higher value, as peoples' perceptions are subject to change. 


\subsection{Risk of bias in the method}

The authors of the current study were all active participants in the analyzed community. All three Pokémon GO teams were represented and both Ingress factions were represented. The chosen word was quite specific, and a similar insightful research setting is not likely to occur at all times in all communities. Despite the birth of the word "jym" being natural, the authors of this paper were participating in using, discussing and criticizing the word among participants before the current study took place. Reportedly some players refused to answer the questionnaire concerning the "jym"-word, as they had such negative feelings towards it. Therefore the results might contain a bias showing more positive attitudes towards the word than what the reality is. Finally, factors such as geographical location or playing activity of participants were not analyzed in the study, even though they likely also have an impact on language acquisition and social circles.

\section{Results}

The questionnaire concerning the word "jym" received 192 responses. After screening the responses for player names and removing those answers which contained excessive foul language, 184 replies were left. Then, further those respondents who did not give permission to use their data in the current study, were removed, resulting in the final number of participants $(\mathrm{N}=178)$. Out of all respondents, 90,4\% $(\mathrm{n}=160)$ said they were familiar with the word. However, the meaning of the word was still understood by the majority of those who said they were unfamiliar with the word, as later on in the questionnaire they managed to give alternative words and phrases to "jym".

\subsection{Usage and attitude towards the jym-word among Pokémon GO players}

Only $27 \%$ of respondents $(n=48)$ replied they were actively using the term "jym", and $5.6 \%(n=10)$ answered that they sometimes used the word. The highest ratio of players who say "jym" was in Team Instinct (44\%), followed by Team Mystic (28\%) and Team Valor $(18 \%)$. Players attitudes towards the word were further explored in the questionnaire, and the results are shown in Figure 1. The attitudes towards the word are quite well in line with the usage of the word, however, what is surprising is the amount of negative reactions towards the word. As expected, Team Valor, who were recorded to have the least players using the word, also had the highest amount of players with a negative attitude towards the word $(52 \%, \mathrm{n}=29)$. Mystic players were the most neutral with $28 \%$ of players stating a negative attitude towards the word and 23 players responding they were indifferent towards the word. Team Instinct was again the leading "jym" -term supporter with only $22 \%$ of players having a negative attitude towards the word.

Five Pokémon Go chats were read and scanned for the usage of the word "jym". The results on the frequency and appearance of "jym" in these chats is shown in Table 1. Unsurprisingly, the frequency and appearance of the term in most cases correlate with the answers to the questionnaire. Players who frequently used the term were also more likely to have positive attitudes towards it. In Case 2 chats of team Valor, whenever a few times "jym" was mentioned, it was criticized or made fun of by members of the community. Those Valor members who had a positive attitude towards the word, were in two instances in the chat recorded to apologize for using it.

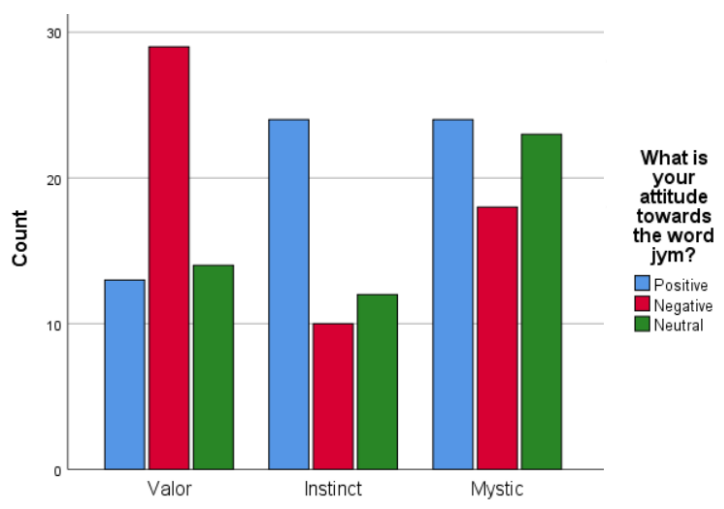

Figure 1. Pokémon GO players attitudes towards the word jym sorted by the team they belong to.

A few outliers in were discovered in the analysis. A team Instinct member was found to have used the word 176 times in a chat, however, in the questionnaire stating a negative attitude towards the word. When interviewed, they explained that upon first joining the chat, they saw players using the word and thought it was official and accepted. However, only later they discovered that in fact the term was only popular in the Instinct chat and a few other chats they belonged to. As reasons for the negative attitude, they stated the unofficial nature of the word and that it was not Finnish. Other outliers were team Valor members who had a positive attitude towards the word, however the majority of them belonged to team Enlightened in Ingress, thus, it is likely they received positive influence towards the word from socializing with users in those circles. 


\begin{tabular}{|c|c|c|c|c|c|c|c|}
\hline \multicolumn{8}{|c|}{ The appearance of jym in five analyzed Pokémon GO chats } \\
\hline & Messages & $\begin{array}{l}\mathbf{N} \quad \text { messages } \\
\text { containing jym }\end{array}$ & $\begin{array}{l}\mathbf{N} \text { times Jym } \\
\text { mentioned }\end{array}$ & $\begin{array}{l}\text { First } \\
\text { appeared }\end{array}$ & As a word & As a subject & Data collected \\
\hline Case 1 Mystic & 90711 & 245 & 393 & $10 / 25 / 2017$ & 392 & 1 & $8 / 14 / 2017-3 / 27 / 2019$ \\
\hline Case 2 Valor & 7931 & 10 & 11 & $1 / 8 / 2019$ & 5 & 6 & $6 / 20 / 2018-6 / 10 / 2019$ \\
\hline Case 3 Instinct & 99798 & 366 & 453 & $3 / 10 / 2018$ & 443 & 6 & 9/21/2016-4/29/2019 \\
\hline Case 4 Common chat & 37864 & 501 & 536 & $3 / 10 / 2018$ & 522 & 10 & $10 / 18 / 2017-1 / 6 / 2019$ \\
\hline Case 5 Mystic2 & 6548 & 347 & 393 & $5 / 4 / 2018$ & 393 & 0 & $5 / 4 / 2018-3 / 27 / 2019$ \\
\hline
\end{tabular}

Table 1. The appearance of jym in five analyzed Pokémon GO chats

\subsection{Ingress players' usage, perceptions and attitudes of "jym"}

With Ingress having less gameplay opportunities for cooperating with the other team, the hypothesis was that attitudes towards "jym" would be more polarized. The results depicted in Figure 2 show that $55 \%$ of team Resistance players perceived the word "jym" negatively, while only $24 \%$ of team Enlightened players perceived the word negatively. Team Resistance also had fewer players with a neutral attitude towards the word. All Ingress players with a positive attitude towards the word also played Pokémon GO. Out of those Ingress players who did not play Pokémon GO $87 \%$ had a negative attitude towards the word.

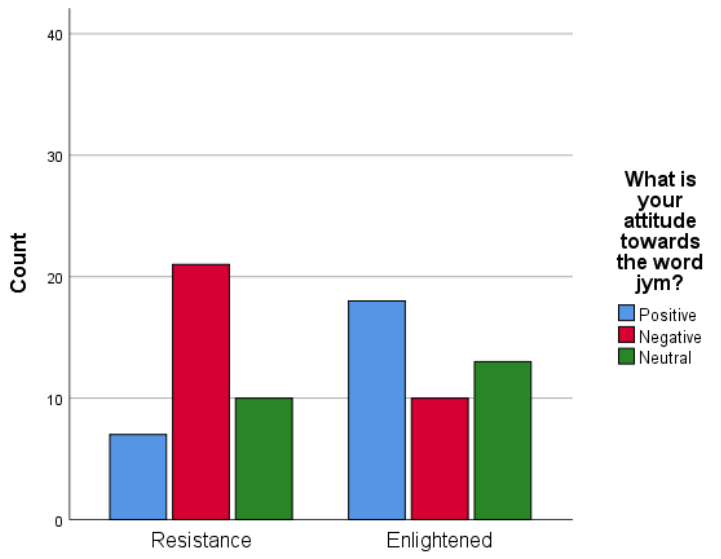

Figure 2. Ingress players attitudes towards the word jym sorted by the team they belong to.

The correlation between the faction of the player in Ingress and the attitude towards "jym" would have probably been stronger if not for certain influences Ingress players got from Pokémon GO circles, as out of the 84 Ingress players who responded to the questionnaire, only 11 reported to never have played Pokémon GO. From the eight Resistance faction agents who reported positive attitudes towards "jym", all played Pokémon GO. (5 Mystic, 2 Instinct, 1 Valor). From the 10 Enlightened agents who reported negative attitude towards "jym”, seven played Pokémon GO (4
Valor, 2 Instinct, 1 Mystic).

\subsection{Derived correlations and causal asymmetry}

Causal asymmetry is understood to be a naturally occurring fallacy in humans, where the importance of the causal object is assigned a higher importance than the object which leads to the outcome [53]. This can partially explain why players felt negative attitudes towards "jym" or players using the word, as they dismissed the important influence of their team and social circles. Perhaps a more accurate theory to describe the situation comes from social psychology, the ingroup-outgroup model which was already discussed in previous sections $[19,21,22]$. The empirical evidence in the current study of players' attitudes towards "jym" can be derived from social circles and friendships. Similar results have been observed in, for example, sporting events [7]. An even stronger causal relationship behind the social circles of Pokémon GO and Ingress was discovered in the data, namely, the players' team. The correlation is amplified, as teams and factions have their own exclusive chats for team members only and a major proportion of written communication between team members occurs there. Previous studies have shown how friendships can be formed via playing online multiplayer games [54], and the effect is arguably stronger in LBGs, where interaction often takes place face-to-face and where the teams are static [55]. Figure 3 shows a derived model of the observed causal relationships and assigned a value (strong-moderate-weak) to represent each causal relationship.

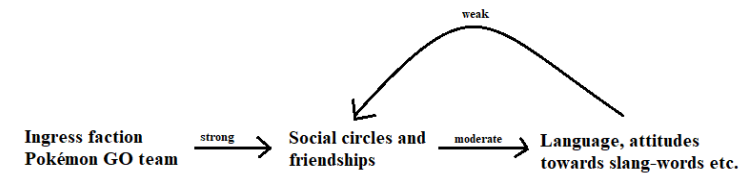

Figure 3. A model constructed based on the findings showing the influence of team choice on players' social circles

Based on reviewed chat logs, LBG players were 
often unaware of their prejudiced attitudes towards players in the enemy team, and furthermore, players in the opposing team were easily perceived as enemies. This kind of an attitude can make playing more fun, and foster a sense of belonging and team spirit among members of the same team [1, 2, 4] whilst simultaneously alienating players on the opposing team $[23,56]$. The model in Figure 3 suggests that when players first started playing Ingress or Pokémon GO and chose their team, they also chose the people they are likely to be hanging out with. This consequently affected their attitudes towards game-related slang.

\section{Discussion}

LBGs are still a new phenomenon, but it is clear from the earliest studies that they foster a sense of belonging for their players, increase the amount of social interaction and provide social gratification [57, $27,4]$. In comparison to other online multiplayer games, which can still have a rich spectrum of interaction [58], LBGs bring people together in the real world. Social interactions in online multiplayer games have been shown to support language acquisition [59], but with LBGs, this phenomenon is now mixed with real life interaction and related learning mechanisms.

\subsection{Why the negative attitudes?}

Interviews with members of the teams (Valor and Resistance) that had the most negative attitudes towards the word "jym", showed that the word was heavily associated with a certain group of active players from Team Mystic. Based on friendship, the use of the word expanded towards certain Ingress players, and especially Team Instinct members, however, never losing the initial association to certain Mystic players, of whom, for example, team Valor had been historically at odds at. Language and word choices have been shown to activate certain areas in the brain causing mental simulations $[60,61]$. For example, food words cause various types of simulations of eating [60]. Studies have also shown the possibility of certain associated language to lead to automatic prejudice towards people [62,63]. This arguably works the other way around, if a group of players are disliked, typical and unique words they use might receive some of that hate as well.

Another reason found for the negative attitudes towards the word "jym", was that it was used in a way which violated the rules of Finnish grammar. Poor grammar is associated with incompetence, and for many employers it is a red flag [64]. The Finnish language belongs to the agglutinative languages meaning it is customary to conjugate words [65] however with the word "jym" and similarly with the word "raid" this was often not done as demonstrated in the analyzed chat logs. The Pokémon GO team that had the most negative attitudes towards "jym" (Team Valor) also almost exclusively used "raid" with proper conjugations. Another linguistic peculiarity is the consonant " $\mathrm{j}$ " which gives a visually powerful and slang-like intonation for the word, as in the Finnish language the written form of words corresponds to the way it is pronounced [43]. This might have been interpreted by some players as an intentional attempt to manipulate language.

A third reason for the birth of negative attitudes, and for some, a reason for sustaining them, was that starting from as early as 2018, "jym" was included in portal candidate submissions [51, 52] made for the Ingress and Pokémon GO games. As Ingress players are in charge of peer reviewing the candidates, this made the word known in the Ingress community, and evidently, not in a positive light. Figure 4 shows an accepted portal submission called "JYM" in southern Finland, which appeared as a gym in Pokémon GO. This portal in question was later renamed to "Puujärven ulkokuntosali", a more accurate description and more properly based on Finnish grammar. The chat material analyzed in the current study shows many perceived the slang-word as a joke or as an insult. This was seen when Ingress players, especially from the Resistance faction, proceeded to submit name edits for portals which contained the word. Several occasions of collaborative celebration were seen in the Resistance faction chats when a portal called "jym" was renamed. In addition, Ingress rules forbid references to real names, faction names, group names etc. in portal titles [66]. Therefore, "jym" as associated with Pokémon GO, was perceived as a violation of these rules by some players.

To summarize, there are several reasons contributing to the negative attitudes towards the word. Firstly, "jym" was associated with a certain group of active players. This caused prejudice towards the word, which was further enhanced by how "jym" was often used with poor grammar. The existing negative attitudes were sustained when players started using the slang-term in portal submission for Ingress. The static teams in Pokémon GO and Ingress, and the lack of cooperative gameplay between teams, especially in Ingress, influenced the whole process as seen in the model in Figure 3. These findings highlight an issue in the game design of Pokémon GO, Ingress and games more generally, where static teams and lack of cross-team cooperation can lead to prejudice and even negative feelings towards players on the enemy team. 


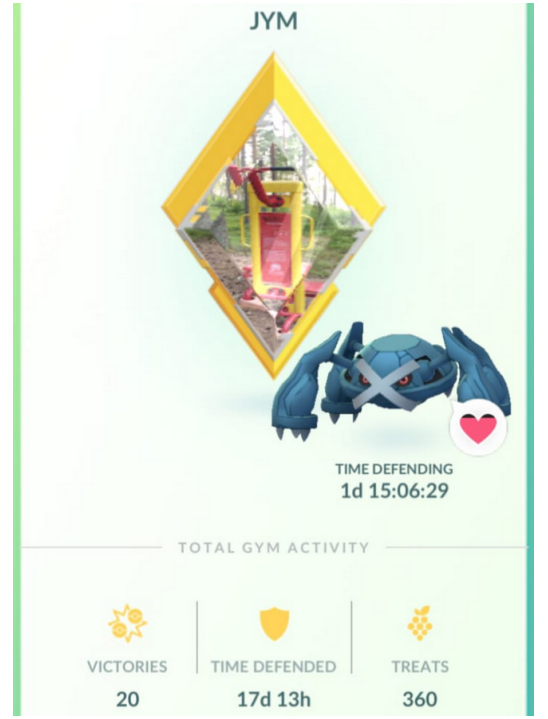

Figure 4. The word "jym" as it appears in an accepted portal turned into a gym in Pokémon GO.

\subsection{Limitations and risk of bias}

Among the limitations of the current study are that there most likely exists countless of chat groups dealing with the word "jym" which the authors did not have access to. Secondly, besides written communication, the word was probably discussed face-to-face while playing, and records of these were not available. Thirdly, the research setup was conditional in the sense that a divisive word similar to "jym" has to be found, in order to be able to carry out a similar study. Also, as the authors were themselves participants in most of the chat groups analyzed, the qualitative analysis of the contents of the chat might be influenced by their knowledge of the community, however, this might have also resulted in a more accurate analysis. Finally, other factors likely influence language acquisition and social circles such as playing activity and geographical location, which were not observed in the current analysis.

\section{Conclusions and Future Work}

Conflict in the game world, paired with static teams which births ingroup-outgroup behavior and related prejudices, and where in-game cooperation possibilities with the enemy team are scarce, can lead to the forming of differences in, for example, the attitudes towards slang words. This is seen in players' attitudes towards the word "jym" and its adoption, which was found to correlate with the players team in Ingress and Pokémon GO. The findings share a similarity to polarization of peoples' opinions due to social media and personalized content $[67,49]$. Communities seem to be eager to collectively either accept or reject slang terms and emerging new words. As a remedy for reducing group polarization, the current study indicates that the root cause needs to be addressed, which is the lack of in-game cooperation opportunities between teams/factions. Pokémon GO has already made changes in that direction, with, for example, raids [9]. However, these changes are difficult to make without losing some of the previously identified benefits of increased cooperation and formed friendship $[9,54,55,1,2,5$, $58,39,7,20,4]$.

Future work can include repeating the study in another part of the world with a similar setting, or with other games, in order to remove doubt of local anomaly. In addition, a continuation study observing the evolution of local slang and its adoption by the community could provide insight into how language evolves, but also into how communities around LBGs such as Ingress and Pokémon GO function. The importance of an opposing outgroup for engagement and motivation in online multiplayer games could also be further explored.

\section{Acknowledgements}

The authors would like to thank Dr Sami Hyrynsalmi and the reviewers and editors of HICSS for their valuable feedback and improvement suggestions as well as Markus Nordblad for providing jym-related consultation and expertise.

\section{References}

[1] L. Humphreys, "Involvement shield or social catalyst: Thoughts on sociospatial practice of pokémon go," Mobile Media \& Communication, vol. 5, no. 1, pp. 15-19, 2017.

[2] L. D. Kaczmarek, M. Misiak, M. Behnke, M. Dziekan, and P. Guzik, "The pikachu effect: Social and health gaming motivations lead to greater benefits of pokémon go use," Computers in Human Behavior, vol. 75, pp. 356-363, 2017.

[3] C. McCrea, "We play in public: The nature and context of portable gaming systems," Convergence, vol. 17, no. 4, pp. 389-403, 2011.

[4] K. Vella, D. Johnson, V. W. S. Cheng, T. Davenport, J. Mitchell, M. Klarkowski, and C. Phillips, "A sense of belonging: Pokemon go and social connectedness," Games and Culture, p. 1555412017719973, 2017.

[5] B. Morschheuser, M. Riar, J. Hamari, and A. Maedche, "How games induce cooperation? a study on the relationship between game features and we-intentions in an augmented reality game," Computers in human behavior, vol. 77, pp. 169-183, 2017.

[6] T. Greitemeyer and C. Cox, "There's no "i" in team: Effects of cooperative video games on cooperative behavior," European Journal of Social Psychology, vol. 43, no. 3, pp. 224-228, 2013. 
[7] F. Ricatti and M. Klugman, "“connected to something': Soccer and the transnational passions, memories and communities of sydney's italian migrants," The International Journal of the History of Sport, vol. 30, no. 5, pp. 469-483, 2013.

[8] J. Ackermann, "Playing computer games as social interaction: An analysis of lan parties," in Computer Games and New Media Cultures, pp. 465-476, Springer, 2012.

[9] A. Bhattacharya, T. W. Windleharth, R. A. Ishii, I. M. Acevedo, C. R. Aragon, J. A. Kientz, J. C. Yip, and J. H. Lee, "Group interactions in location-based gaming: A case study of raiding in pokémon go," in Proceedings of the 2019 CHI Conference on Human Factors in Computing Systems, p. 587, ACM, 2019.

[10] R. Li, S. Liu, Y. Liu, H.-Y. Tu, and X. Yang, "A probe into ingress and its social interaction: augmented reality's influence on mobile game community design," vince-li. com. http://vince-li. com/pdf/ingress/paper. pdf. Accessed, vol. 28, 2016.

[11] J. M. Vaterlaus, K. Frantz, and T. Robecker, “"reliving my childhood dream of being a pokémon trainer": An exploratory study of college student uses and gratifications related to pokémon go," International Journal of Human-Computer Interaction, vol. 35, no. 7, pp. 596-604, 2019.

[12] J. Blackburn and H. Kwak, "Stfu noob!: predicting crowdsourced decisions on toxic behavior in online games," in Proceedings of the 23rd international conference on World wide web, pp. 877-888, ACM, 2014.

[13] B. Kordyaka, M. Klesel, and K. Jahn, "Perpetrators in league of legends: Scale development and validation of toxic behavior," in Proceedings of the 52nd Hawaii International Conference on System Sciences, 2019.

[14] H. Kwak, J. Blackburn, and S. Han, "Exploring cyberbullying and other toxic behavior in team competition online games," in Proceedings of the 33rd Annual ACM Conference on Human Factors in Computing Systems, pp. 3739-3748, ACM, 2015.

[15] R. Potts and L. Yee, "Pokémon go-ing or staying: exploring the effect of age and gender on augmented reality game player experiences in public spaces," Journal of Urban Design, pp. 1-18, 2019.

[16] S. R. Burgess, S. P. Stermer, and M. C. Burgess, "Video game playing and academic performance in college students.," College Student Journal, vol. 46, no. 2, 2012.

[17] R. Kircher and S. Fox, "Attitudes towards multicultural london english: implications for attitude theory and language planning," Journal of Multilingual and Multicultural Development, pp. 1-18, 2019.

[18] N. Alomar, M. Alsaleh, and A. Alarifi, "Behavioral consequences of pokémon go: The exaggerated picture," Computers in Human Behavior, vol. 90, pp. 223-245, 2019

[19] M. B. Brewer, "The psychology of prejudice: Ingroup love and outgroup hate?," Journal of social issues, vol. 55, no. 3, pp. 429-444, 1999.

[20] J. A. Velez, C. Mahood, D. R. Ewoldsen, and E. Moyer-Gusé, "Ingroup versus outgroup conflict in the context of violent video game play: The effect of cooperation on increased helping and decreased aggression," Communication Research, vol. 41, no. 5, pp. 607-626, 2014.
[21] W. B. Gudykunst, Y.-C. Yoon, and T. Nishida, "The influence of individualism-collectivism on perceptions of communication in ingroup and outgroup relationships," Communications Monographs, vol. 54, no. 3, pp. 295-306, 1987.

[22] J. M. Rabbie and M. Horwitz, "Arousal of ingroup-outgroup bias by a chance win or loss.," Journal of personality and social psychology, vol. 13, no. 3, p. 269, 1969.

[23] J. H. Tan and D. J. Zizzo, "Groups, cooperation and conflict in games," The Journal of Socio-Economics, vol. 37, no. 1, pp. 1-17, 2008.

[24] S. Laato., T. Pietarinen., S. Rauti., M. Paloheimo., N. Inaba., and E. Sutinen., "A review of location-based games: Do they all support exercise, social interaction and cartographical training?," in In the 11th CSEDU Volume 1, pp. 616-627, INSTICC, SciTePress, 2019.

[25] H. Söbke, J. B. Hauge, and I. A. Stefan, "Prime example ingress reframing the pervasive game design framework (pgdf)," International Journal of Serious Games, vol. 4, no. 2, 2017.

[26] P. Karpashevich, E. Hornecker, N. K. Dankwa, M. Hanafy, and J. Fietkau, "Blurring boundaries between everyday life and pervasive gaming: an interview study of ingress," in Proceedings of the 15th International Conference on Mobile and Ubiquitous Multimedia, pp. 217-228, ACM, 2016.

[27] L. Y. Sheng, "Modelling learning from ingress (google's augmented reality social game)," in 2013 IEEE 63rd annual conference international council for education media (ICEM), pp. 1-8, IEEE, 2013.

[28] C. Tokgöz and B. Polat, "Sociability on location based mobile games: An ethnographic research on pokémon go and ingress in istanbul," European Journal of Social Science Education and Research, vol. 5, no. 1, pp. 111-120, 2018.

[29] S. Fragoso and B. M. S. Reis, "Ludic re-enchantment and the power of locative games: A case study of the game ingress," in International Conference on Culture, Technology, and Communication, pp. 131-148, Springer, 2016.

[30] A. Shirai, Y. Kose, K. Minobe, and T. Kimura, "Gamification and construction of virtual field museum by using augmented reality game ingress," in Proceedings of the 2015 Virtual Reality International Conference, p. 4, ACM, 2015.

[31] T. Althoff, R. W. White, and E. Horvitz, "Influence of pokémon go on physical activity: study and implications," Journal of medical Internet research, vol. 18, no. 12, p. e315, 2016.

[32] M. Tateno, N. Skokauskas, T. A. Kato, A. R. Teo, and A. P. Guerrero, "New game software (pokémon go) may help youth with severe social withdrawal, hikikomori," Psychiatry research, vol. 246, p. 848, 2016.

[33] J. E. Barkley, A. Lepp, and E. L. Glickman, ““"pokémon go!" may promote walking, discourage sedentary behavior in college students," Games for health journal, vol. 6, no. 3, pp. 165-170, 2017.

[34] T. Oleksy and A. Wnuk, "Catch them all and increase your place attachment! the role of location-based augmented reality games in changing people-place relations," Computers in Human Behavior, vol. 76, pp. 3-8, 2017. 
[35] C. R. Nigg, D. J. Mateo, and J. An, "Pokémon go may increase physical activity and decrease sedentary behaviors," American journal of public health, vol. 107, no. 1, p. 37, 2017.

[36] M. Serino, K. Cordrey, L. McLaughlin, and R. L. Milanaik, "Pokémon go and augmented virtual reality games: a cautionary commentary for parents and pediatricians," Current opinion in pediatrics, vol. 28 , no. 5, pp. 673-677, 2016.

[37] Niantic, "Raid battles now available, https://pokemongolive.com/en/post/raidsrollout/," 2019.

[38] Niantic, "Make way for friends, trading and gifting in pokemon go https://pokemongolive.com/en/post/friendsandtrading/," 2019.

[39] S. Paasovaara, P. Jarusriboonchai, and T. Olsson, "Understanding collocated social interaction between pokémon go players," in Proceedings of the 16th International Conference on Mobile and Ubiquitous Multimedia, pp. 151-163, ACM, 2017.

[40] A. Peysakhovich and D. G. Rand, "In-group favoritism caused by pokémon go and the use of machine learning for principled investigation of potential moderators," Available at SSRN 2908978, 2017.

[41] A. Cacchione, E. Procter-Legg, and S. A. Petersen, "\# gottacatchemall: Exploring pokemon go in search of learning enhancement objects.," International Association for Development of the Information Society, 2017.

[42] N. Ratner and J. Bruner, "Games, social exchange and the acquisition of language," Journal of child language, vol. 5, no. 3, pp. 391-401, 1978.

[43] K. Ojutkangas, M. Larjavaara, M. Miestamo, and J. Ylikoski, Johdatus kielitieteeseen. WSOY oppimateriaalit, 2009.

[44] J. Coleman, The life of slang. OUP Oxford, 2012.

[45] R. Jones, Internet Slang Dictionary. Lulu. com, 2006.

[46] J. Olejniczak et al., "A linguistic study of language variety used on twitch. tv: desriptive and corpus-based approaches," Redefining Community in Intercultural Context, vol. 4, no. 1, pp. 329-334, 2015.

[47] C. R. Sunstein, "The law of group polarization," Journal of political philosophy, vol. 10, no. 2, pp. 175-195, 2002.

[48] A. J. Setterstrom and J. M. Pearson, "Social influence and willingness to pay for massively multiplayer online games: An empirical examination of social identity theory," Communications of the Association for Information Systems, vol. 44, no. 1, p. 2, 2019.

[49] J. K. Lee, J. Choi, C. Kim, and Y. Kim, "Social media, network heterogeneity, and opinion polarization," Journal of communication, vol. 64, no. 4, pp. 702-722, 2014.

[50] D. Spohr, "Fake news and ideological polarization: Filter bubbles and selective exposure on social media," Business Information Review, vol. 34, no. 3, pp. 150-160, 2017.

[51] T. Tregel, L. Raymann, S. Göbel, and R. Steinmetz, "Geodata classification for automatic content creation in location-based games," in Joint International Conference on Serious Games, pp. 212-223, Springer, 2017.
[52] S. Laato., T. Pietarinen., S. Rauti., and T. H. Laine, "Analysis of the quality of points of interests in the most popular location-based games," in Proceedings of CompSysTech19, Sofia, Bulgaria, ACM, 2019.

[53] P. A. White, "The causal asymmetry.," Psychological Review, vol. 113, no. 1, p. 132, 2006.

[54] H. Cole and M. D. Griffiths, "Social interactions in massively multiplayer online role-playing gamers," Cyberpsychology \& behavior, vol. 10, no. 4, pp. 575-583, 2007.

[55] M. D. Finco, "I play, you play and we play together: Social interaction through the use of pokémon go," in Augmented Reality Games I, pp. 117-128, Springer, 2019.

[56] D. L. Wann and F. G. Grieve, "Biased evaluations of in-group and out-group spectator behavior at sporting events: The importance of team identification and threats to social identity," The journal of social psychology, vol. 145, no. 5, pp. 531-546, 2005.

[57] J. Hamari, A. Malik, J. Koski, and A. Johri, "Uses and gratifications of pokémon go: Why do people play mobile location-based augmented reality games?," International Journal of Human-Computer Interaction, vol. 35, no. 9, pp. 804-819, 2019.

[58] B. Nardi and J. Harris, "Strangers and friends: Collaborative play in world of warcraft," in Proceedings of the 2006 20th anniversary conference on Computer supported cooperative work, pp. 149-158, ACM, 2006.

[59] Y. A. Rankin, D. Morrison, M. McNeal, B. Gooch, and M. W. Shute, "Time will tell: In-game social interactions that facilitate second language acquisition," in Proceedings of the 4th international conference on foundations of digital games, pp. 161-168, ACM, 2009.

[60] E. K. Papies, "Tempting food words activate eating simulations," Frontiers in psychology, vol. 4, p. 838, 2013.

[61] F. Pulvermüller, "Brain mechanisms linking language and action," Nature reviews neuroscience, vol. 6 , no. 7 , p. $576,2005$.

[62] G. B. Maddox, M. Naveh-Benjamin, S. Old, and A. Kilb, "The role of attention in the associative binding of emotionally arousing words," Psychonomic bulletin \& review, vol. 19, no. 6, pp. 1128-1134, 2012.

[63] E. L. Uhlmann, V. L. Brescoll, and E. L. Paluck, "Are members of low status groups perceived as bad, or badly off? egalitarian negative associations and automatic prejudice," Journal of Experimental Social Psychology, vol. 42, no. 4, pp. 491-499, 2006.

[64] K. Wiens, "I won't hire people who use poor grammar. here's why.," Harvard Business Review, 2012.

[65] L. Löfberg, D. Archer, S. Piao, P. Rayson, T. McEnery, K. Varantola, and J.-P. Juntunen, "Porting an english semantic tagger to the finnish language," in Proceedings of the Corpus Linguistics 2003 conference, pp. 457-464, 2003.

[66] Niantic, "Candidate portal criteria, https://ingress.com/support," 2019.

[67] M. D. Conover, J. Ratkiewicz, M. Francisco, B. Gonçalves, F. Menczer, and A. Flammini, "Political polarization on twitter," in Fifth international AAAI conference on weblogs and social media, 2011. 